\title{
Nilai Kerja Pada Wanita Yang Bekerja
}

\author{
Nugroho Hadi Nur Hendri Putranto dan Tri Muji Ingarianti ${ }^{1}$ \\ Fakultas Psikologi Universitas Muhammadiyah Malang
}

\begin{abstract}
Value can be defined as the work the general belief about the desirability of various aspects of employment (eg, salary, autonomy, working conditions), and work-related outcomes (eg, achievement, fulfillment, prestige). It's important to note that the value of the work did not evaluate certain aspects of the work or the result, but the underlying criteria used to perform the evaluation. This study used a non-experimental method which quantitative descriptive approach wich aims to reveal the value of labor in women who work. The research sample of 100 women who worked in the city of Malang. With a value scale work consisting of 98 items statement, found the results of the analysis of the Z-Score with the acquisition of a percentage on each level of the value of work starting from the highest rank is the dimension of the value of autonomy (Autonomy), which is as much as 28\% or 28 people, followed by value of achievement (Achievement) and the principle of putting others (Altruism) which had the same percentage as much as 20\%, and the next is the value of the status (Status) with a percentage of 18\%, next is the value of comfort (Comfort) with a percentage of 14\%, while the lower value is the value of the security (Safety) with a percentage gain as much as $0 \%$.
\end{abstract}

Keywords : Work Values, Women That Work.

\begin{abstract}
Abstrak: Nilai kerja dapat didefinisikan sebagai keyakinan umum mengenai keinginan dari berbagai aspek pekerjaan (misalnya, gaji, otonomi, kondisi kerja), dan hasil yang berhubungan dengan pekerjaan (misalnya, prestasi, pemenuhan, prestise).Sangat penting untuk dicatat bahwa nilai kerja tidak mengevaluasi aspek pekerjaan tertentu atau hasil, tetapi kriteria yang mendasari yang digunakan untuk melakukan evaluasi tersebut. Penelitian ini menggunakan metode non eksperimental yang menggunakan pendekatan kuantitatif deskriptif yang bertujuan untuk mengetahui gambaran nilai kerja pada wanita yang bekerja. Sampel penelitian berjumlah 100 orang wanita yang bekerja di kota Malang. Dengan skala nilai kerja yang terdiri dari 98 item pernyataan, ditemukan hasil analisa Z-Score dengan perolehan prosentase pada masing-masing tingkat nilai kerja dimulai dari ranking tertinggi adalah dimensi nilai otonomi (Autonomy), yaitu sebanyak $28 \%$ atau 28 orang, kemudian diikuti dengan nilai prestasi (Achievement) dan azas mengutamakan orang lain (Altruism) yang sama-sama memiliki prosentase sebanyak 20\%, dan berikutnya adalah nilai status (Status) dengan prosentase 18\%, selanjutnya adalah nilai kenyamanan (Comfort) dengan prosentase sebanyak 14\%, sedangkan nilai terbawah adalah nilai keamanan (Safety) dengan perolehan prosentase sebanyak 0\%.
\end{abstract}

Kata kunci : Nilai Kerja, Wanita Yang Bekerja.

Di tengah dinamika dunia yang terus berkembang, ternyata tuntutan hidup-pun tidak lagi sederhana. Dulu, gambaran generasi 90-an ke bawah banyak yang berpandangan ketika mereka berkeluarga, bahwa tugas pria itu mencari nafkah dan wanita (isteri) menjaga dan mengelola rumah dan seisinya. Kini, sudut pandang seperti itu bukan lagi menjadi arus utama pikiran sejumlah keluarga. Saat ini, yang mencari nafkah untuk memenuhi kebutuhan keluarga bukan hanya para suami, namun juga tidak sedikit para isteri yang sama-sama keluar rumah untuk memenuhi sebuah pekerjaan. Dan dari hari ke hari

\footnotetext{
${ }^{1)}$ Korespondensi tentang artikel ini dapat dialamatkan kepada Nugroho Hadi Nur Hendri Putranto melalui e-mail: nugrohohadi_nhp@yahoo.com; atau kepadaTri MujiIngariantimelalui e-mail:tri_ingarianti@yahoo.com.
} 
sejumlah pekerjaan pada berbagai sektor-pun secara perlahan dimasuki oleh kalangan wanita. Dengan ditunjang oleh kualitas personal, sejumlah relasi dan jaringan yang dimiliki, kini dengan sendirinya tak ada lagi sekat-sekat yang membedakan antara pria dengan para wanita yang ingin meniti karir di dunia kerja.

Tak heran kini, jumlah pekerja perempuan di Indonesia tercatat sudah mencapai 35,37 persen dari 100 juta angkatan kerja. Kondisi ini menunjukkan bahwa pekerja perempuan sudah menjadi arus utama di sebagian besar perusahaan ataupun industri. (http://kompasiana.com/ibu-dananak/2011/04/06/perempuan-dalamdilemma-pengasuhan- anak-pekerjaan/)

Segala sesuatunya berubah secara perlahan-lahan selama abad terakhir, partisipasi wanita dalam dunia kerja dibatasi oleh praktek-praktek budaya, pendidikan, dan hukum tradisional. Wanita yang bekerja di luar rumah dan menikah dibatasi untuk beberapa pekerjaan seperti pelayanan rumah tangga, kerja pabrik, pekerjaan pertanian, dan pengajaran. Selama beberapa dekade terakhir, angkatan kerja wanita di Amerika Serikat dan di seluruh dunia telah mengalami banyak perubahan. Tenaga kerja tingkat partisipasi kalangan wanita secara signifikan lebih tinggi hari ini dibandingkan pada tahun 1970-an. Sepanjang periode itu, wanita telah semakin mencapai tingkat pendidikan yang lebih tinggi dan mengalami peningkatan pendapatan mereka sebagai proporsi dari pendapatan pria. (http://www.bls.gov/ spotlight/2011/women at work).

Situasi bagi perempuan telah sangat berubah. Metode kontrasepsi modern telah memungkinkan perempuan untuk membatasi jumlah anak yang mereka miliki dan sering kali merencankan kehamilan, agar seminimal mungkin sehingga tidak mengganggu karir mereka. Dengan perawatan kedokteran modern, perempuan mengalami komplikasi lebih sedikit selama kehamilan dan kelahiran. Pengasuhan anak telah berubah juga. Beban domestik relatif ringan dalam masyarakat modern dan berbagai jenis fasilitas perawatan anak telah tersedia.

Pengaruh dari berbagai perubahan ini telah menciptakan masyarakat yang menciptakan tuntutan tugas bagi laki-laki dan perempuan yang sangat berbeda pada hal yang sama di masa lalu. Laki-laki tidak lagi memperoleh penghormatan yang menguntungkan dari kekutan fisik yang superior, perempuan tidak lagi terbatas hanya pada melahirkan dan merawat anak-anak serta melakukan tugas-tugas rumah tangga. Perempuan yang secara ekonomi mandiri tidak memiliki kebutuhan ekonomis untuk menikah, maka mereka merasa tekanan yang lebih sedikit untuk menikah. Mereka mungkin menikah untuk alasan-alasan yang lain, tetapi pernikahan bukan pilihan mereka satusatunya. Dan mereka yang memilih untuk tidak menjadi ibu, meskipun menikah, mungkin berhubungan dengan laki-laki dalam cara yang sangat berbeda daripada perempuan yang memang memilih menjadi ibu.

Perubahan peran perempuan jelas terjadi sejalan dengan meningkatnya tingkat pekerjaan perempuan (DeCorte, 1993; London \& Greller 1991; Morisson, 1993). Pada tahun 1960 hanya sepertiga dari seluruh perempuan bekerja yang memiliki anak; tetapi di tahun 1988 , 55 persen dari perempuan yang menikah dengan bayi dan 61 persen dari seluruh perempuan yang memiliki anak belum sekolah bekerja di luar rumah. Pekerjaan perempuan juga berubah. Empat dari sepuluh mahasiswi kini bermaksud mengejar karir dalam bidang hukum, bisnis, pengobatan, atau teknik, sedangkan pada tahun 1970 hanya dua dari sepuluh perempuan mengatakan bermaksud mengejar karir yang didominasi oleh laki-laki (Astin, Green \& Korn, 1987). Dalam satu penelitian baru-baru ini, orientasi peran gender berhubungan 
dengan stres yang dialami perempuan dalam pekerjaan yang didominasi oleh laki-laki (Long, 1989). Perempuan yang sangat maskulin (terbuka/asertif) dilaporkan tidak banyak mengalami kecemasan dan bertahan dalam pekerjaannya daripada perempuan yang tingkat maskulinnya rendah.

Saat ini perempuan mengisi hampir satu per tiga dari posisi manajemen, sebuah peningkatan dari hanya 19 persen pada tahun 1972, meski sebagian besar berada dalam pekerjaan dengan kekuasaan yang kecil dan berupah rendah (Paludi, 1992). Hanya 2 persen eksekutif senior adalah perempuan, dan hanya 1,7 persen dari staff perusahaan Fortune 500 adalah perempuan. Perhatian khusus tentang perkembangan karir perempuan, seperti juga individu dari etnis minoritas, adalah pengalaman dari "kaca pembatas" dalam manajemen.

Konsep kaca pembatas sangat populer di tahun 1980-an untuk menggambarkan hambatan utama yang tidak tampak jelas, tetapi secara kuat menghalangi perempuan naik dalam hierarki manajemen. Diskriminasi ini masih sering menggambarkan bahwa "manajer yang baik" memiliki sifat "maskulin" daripada "androgini", atau kompeten dalam berbagai organisasi (Morisson \& Von Glinow, 1990).

Mengenai perbedaan gender dalam dunia kerja ini secara tidak langsung juga berhubungan dengan nilai-nilai, Super (1995) mengutip penelitian (misalnya, Nevill \& Super, 1989) yang mendukung gagasan bahwa wanita cenderung memiliki nilai yang kurang dalam hubungan sosial dan otoritas lebih daripada pria. Lainnya, seperti Eccles (1994), mempelajari peran nilai tugas subjektif dalam pilihan utama dan pekerjaan.

Ada sedikit atau tidak ada penelitian empiris yang dipublikasikan dalam literatur penelitian berfokus pada perbedaan gender dalam arti penting pada nilai-nilai berbagai pekerjaan. Namun, tampaknya jelas bahwa eksplorasi perbedaan gender merupakan kontribusi penting pada studi tentang nilai kerja.

Secara khusus, Eccles (1994) berteori bahwa sosialisasi gender yang dapat menyebabkan wanita dan pria memiliki hierarki yang berbeda dari nilai-nilai pribadi inti. Dalam studi longitudinalnya transisi kehidupan remaja, ia menemukan bahwa anak perempuan memiliki nilai lebih daripada anak laki-laki tentang pentingnya mengorbankan pekerjaan demi keluarga. Wanita juga dinilai memiliki pekerjaan yang memungkinkan seseorang untuk membantu orang lain dan melakukan sesuatu bagi masyarakat. Para pria, sebaliknya, pada tugas-tugas berikut merasa lebih penting daripada para wanita: menjadi terkenal, memiliki banyak uang, melakukan pekerjaan yang melibatkan penggunaan matematika dan komputer, dan mencari tugas-tugas yang menantang.

Sehubungan dengan sistem yang lebih luas nilai budaya individualisme dan kolektivisme, beberapa penelitian tentang perbedaan gender telah diterbitkan. Sebagai contoh, Triandis dkk. (1995), mencatat bahwa deskripsi kolektivisme dan individualisme bergema deskripsi dari perbedaan antara perempuan dan laki-laki, menjelajahi perbedaan gender dalam kolektivisme dan individualisme. Pada awal penelitian para penulis berhipotesis bahwa "wanita akan lebih kolektif daripada pria". Dan hasilnya ternyata sesuai hipotesis para penulis, yaitu wanita menunjukkan kecenderungan signifikan lebih kolektif atau allocentric daripada pria, dan para pria lebih mendukung sikap individualistis atau idiocentric daripada wanita. (Kuhn \& McPartland, 1954; seperti dikutip oleh Triandis dkk).

Untuk kaitan arti kerja dengan produktivitas masih ada beberapa hal yang perlu diperhatikan. Nilai-nilai kerja dan interes utama dalam hidup merupakan dua hal lain dan beberapa hal yang punya kaitan erat 
dengan produktivitas. Nilai kerja semata-mata sering hanya menjadi sesuatu yang artifisial bila hal lain tidak mendukung. Sayangnya, literatur yang masih ada tentang nilai kerja yang ada sekarang hanya ada sedikit, dan berbagai upaya telah dilakukan untuk menyelidiki perbedaan-perbedaan tersebut secara empiris (Karp \& Sirias, 2001).

Berdasarkan uraian di atas, nilai kerja merupakan aspek penting bagi wanita dalam menjalankan perannya sebagai karyawan. Melihat akan pentingnya nilai kerja bagi seorang wanita, maka dari itu dalam penelitian kali ini muncul pertanyaan bagaimana gambaran atau deskripsi mengenai nilai kerja pada wanita yang bekerja? Yang mana penelitian ini memiliki tujuan untuk mengetahui gambaran atau deskripsi mengenai nilai kerja pada wanita yang bekerja.

Penelitian ini diharapkan dapat memberikan manfaat pada setiap pihak yang membaca dan berkaitan dengan penelitian ini. Selain itu, penelitian ini diharapkan bisa memberikan sumbangan wacana dan informasi bagi psikologi secara umum, khususnya psikologi industri dan organisasi, serta mampu memberikan sumbangan saran dan tindakan yang berarti berkenaan dengan nilai kerja pada wanita yang bekerja. Penelitian ini juga diharapkan dapat dijadikan suatu rujukan atau pertimbangan bila akan mengadakan penelitian lebih lanjut, khususnya masalah nilai kerja pada wanita yang bekerja agar mendapatkan hasil yang lebih baik pada penelitiannya.

\section{Nilai Kerja}

Sejumlah teori pengembangan karir banyak yangmendiskusikan nilai kerja (Dawis, 2005; Super et al, 1957.). Dalam "Theoryof Work Adjustment", nilai kerja dikonseptualisasikansebagai sebuah aspek pekerjaan yang diperlukan untuk mendapatkan kepuasan kerja (Dawis \& Lofquist, 1984). Donald Super (1980, hal. 130) mendefinisikan nilai kerja sebagai "suatu keadaan psikologis, hubungan, atau kondisi material dari tiap individu yang berusaha untuk mencapai sebuah tujuan". Banyak definisi yang muncul mengenai hal ini, dan sangat bervariasi, namun Zytowski (1994) mencatat bahwa dalam semua literatur psikologi, nilai kerja paling sering ditandai sebagai motif penguat positif dari kepuasan kerja.

Penelitian empiris pada nilai kerja telah menemukan bahwa nilai kerja dapat memprediksi kepuasan kerja (Dawis, 2002; Rounds, 1990) dan minat khusus (Berings, De Fruyt, \& Bouwen, 2004) dan terkait dengan pilihan karir (Kalleberg \& Stark, 1993; Young, 1984; Zytowski, 1994) dan kinerja dalam sebuah pekerjan (Swenson \& Herche, 1994). Selanjutnya, pertemuan antara nilai-nilai karyawan dan penguatan nilai-nilai di tempat kerja dapat memprediksi masa jabatan, niat untuk tetap bekerja pada sebuah pekerjaan (Hesketh, McLachlan, \& Gardner, 1992), dan kepuasan kerja (Bizot \& Goldman, 1993).

\section{Nilai Kerja dalam Teori Penyesuaian Pekerjaan(Theoryof Work Adjustment)}

Penelitian tentang teori penyesuaian pekerjaan dimulai pada tahun 1957 oleh proyek penyesuaian pekerjaan di Universitas Minnesota di bawah arahan René Dawis dan Lloyd Lofquist. Teori penyesuaian pekerjaan menganggap bahwa dimensi nilai adalah sebuah set interrelationship yang kompleks yang dapat diamati dan dapat diasosiasikan dengan satu atau beberapa kebutuhan (needs) serta menyediakan sebuah cara yang mudah (manageable) untuk mendeskripsikan kebutuhan (need) seorang individu.Dimensi nilai ini juga menjadi karakteristik penting yang relevan dari individu-individu untuk menentukan hubungan antara individu dan lingkungan kerja. Nilaisebagai standar arti penting untuk tiap individu, mereka mempengaruhi pilihan lingkungan, dan 
mempengaruhi persepsi dan kepuasan dengan kondisi-kondisi lingkungan kerja.

Dimensi nilai dalam struktur kepribadian kerja dapat diidentifikasi dari analisis pekerjaan terkait dengan dimensi kebutuhan. Minessota Importance Questionnaire yang telah dikembangkan oleh proyek penyesuaian pekerjaan di Universitas Minnestota, dirancang untuk menilai 20 dimensi kebutuhan yang relevan dengan pekerjaan: Penggunaaan kemampuan (Ability Utilization), Prestasi (Achievement), Kegiatan (Activity), Kebebasan (Independence), Variasi (Variety), Kompensasi (Compensation), Keamanan (Security), Kondisi kerja (Working Conditions), Kemajuan (Advancement), Pengakuan (Recognition), Wewenang (Authority), Status sosial (Social Status), Rekan kerja (Co-Workers), Nilai moral (Moral Value), Layanan sosial (Social Service), Praktek kebijakan perusahaan (Company Policies and Practices), Pengawas relasi manusia (Supervision Human Relations), Pengawas teknis (Supervision Technical), Kreativitas (Creativity), Tanggung jawab (Responsibilty).
Analisis faktor data Minessota Importance Questionnaire menunjukkan bahwa enam faktor dimensi nilai dapat mewakili 20 dimensi kebutuhan. Oleh karena itu, faktor-faktor ini dapat digunakan sebagai dimensi acuan untuk deskripsi kebutuhan dan dapat disebut juga sebagai dimensi nilai. Keenam dimensi nilai tersebut adalah sebagai berikut: Prestasi (Achievement), menunjukkan pentingnya lingkungan yang mendorong untuk berprestasi; Kenyamanan (Comfort) berkaitan dengan pentingnya lingkungan yang nyaman dan tidak mudah menyebabkan tekanan jiwa (stress); Status (Status), berkaitan dengan pentingnya lingkungan yang memberikan pengakuan dan penghargaan (prestige); Azas Mengutamakan Orang Lain (Altruism) terkait dengan pentingnya suatu lingkungan yang mendorong keharmonisan dan mengutamakan pelayanan kepada orang lain; Keamanan (Safety), merujuk pada pentingnya lingkungan yang dapat diprediksi dan stabil; dan Otonomi (Autonomy), berkaitan dengan pentingnya lingkungan yang selalu merangsang inisiatif untuk selalu mandiri.

Tabel 1. Deskripsi Nilai Dan Kebutuhan

\begin{tabular}{ll}
\hline \multicolumn{1}{c}{ Nilai (Value) } & \multicolumn{1}{c}{ Kebutuhan (Need Scale) } \\
\hline Prestasi (Achievement) & Penggunaan kemampuan (Ability Utilization) \\
& Prestasi (Achievement) \\
& Kegiatan ( ctivity) \\
& Kebebasan (Independence) \\
Kenyamanan(Comfort) & Variasi (Variety) \\
& Kompensasi (Compensation) \\
& Keamanan (Security) \\
& Kondisi kerja (Working Conditions) \\
& Kemajuan (Advancement) \\
\hline Status(Status) & Pengakuan (Recognition) \\
& Wewenang (Authority) \\
& Status sosial (Social Status) \\
\hline Azas Mengutamakan Orang Lain & Rekan kerja (Co-Workers) \\
(Altruism) & Nilai moral (Moral Value) \\
& Layanan sosial (Social Service) \\
Keamanan (Safety) & Praktek kebijakan perusahaan (Company Policies and \\
& Practices) \\
& Pengawasrelasi manusia (Supervision Human \\
& Relations) \\
& Pengawas teknis (Supervision Technical) \\
\hline Otonomi (Autonomy) & Kreativitas (Creativity) \\
& Tanggung jawab (Responsibilty) \\
\hline
\end{tabular}


Dari 20 kebutuhan diatas mungkin memiliki arti penting untuk semua individu. Mereka mendasari atau membuatnya dari suatu sampling yang mewakili kebutuhan itu semua dan menemukannya sebagai kebutuhan yang paling penting dalam hubungan dengan bekerja. Kebutuhan ini mungkin lebih lanjut diuraikan dalam kaitan dengan kondisi-kondisi pada lingkungan kerja yang mencukupi kebutuhan mereka, yaitu, dalam kaitan dengan lingkungan mereka dan menjadi suatu reinforcers (penguat).

\section{METODE}

Desain penelitian kali ini adalah penelitian non eksperimental (Kerlinger, 2000), yaitu telaah empirik sistematis di mana ilmuwan tidak dapat mengontrol secara langsung variabel karena manifestasinya telah muncul atau karena sifat hakekat variabelnya yang menutup kemungkinan untuk dilakukan manipulasi. Desain penelitian non eksperimental ini menggunakan pendekatan kuantitatif deskriptif yang mana hasil penelitian ini ditujukan untuk mendeskripsikan data yang berupa angka-angka agar mampu dipahami sesuai dengan definisi atau makna angka-angka tersebut sehingga mampu menjawab rumusan masalah.

\section{Sampel}

Di dalam penelitian ini yang menjadi karakteristik subjek penelitian adalah para wanita yang bekerja lebih dari dua tahun dibeberapa perusahaan milik swasta dan beberapa intansi pemerintah di kota Malang. Peneliti mengambil sampel sejumlah 100 orang.

Pengumpulan data menggunakan teknik quota sampling dengan menentukan jumlah subjek penelitian yang akan diambil terlebih dahulu. Dipilih teknik quota sampling karena banyaknya jumlah wanita yang bekerja yang terdapat di kota Malang, sehingga perlu ditentukan jumlah sampel agar memudahkan penyebaran skala dan penentuan sampel.

\section{Teknik Pengumpulan Data}

Variabel penelitian ini adalah variabel tunggal, yaitu satu-satunya variabel yang diukur dalam suatu penelitian. Berdasarkan latar belakang dan kajian teori, variabel tunggal yang akan diukur dalam penelitian ini adalah nilai kerja.

Telah banyak banyak teori yang tertulis di kajian pustaka yang menerangkan tentang variabel yang akan diukur, namun agar mendapat kejelasan arti sehingga memudahkan pengukuran, maka variabel perlu dijabarkan dalam suatu definisi operasional. Definisi operasional nilai kerja yaitu sebuah keyakinan umum yang diasosiasikan dengan satu atau beberapa kebutuhan (needs) yang dapat diamati dari ekspresi kognitif sesorang dalam kehidupan kerjanya.

Skala yang digunakan untuk mengukur nilai kerja dalam penelitian ini menggunakan adaptasi dari Minessota Importance Questionnaire yang telah dikembangkan oleh proyek penyesuaian pekerjaan di Universitas Minnestota, yang dimulai pada tahun 1957 di bawah arahan René Dawis dan Lloyd Lofquist disusun dan dirancang untuk menilai 6 dimensi nilai yang dapat diidentifikasi dari analisis pekerjaan terkait dengan 20 dimensi kebutuhan yang relevan dengan pekerjaan. Dari 100 pernyataan yang diujicobakan, hanya ada 98 pernyataan yang valid dan reliabel.

Penilaian skala nilai kerja mengikuti skala Likert, tapi nilainya bergerak dari angka satu sampai angka lima. Hal ini dimaksudkan agar terhindar dari jawaban yang netral. Pada butir akan didapat nilai sebagai berikut : skor 5 untuk jawaban Sangat Setuju (SS); 4 untuk jawaban Setuju (S); 3 untuk jawaban Tidak 
Setuju (N); 2 untuk jawaban Tidak Setuju (TS); 1 untuk jawaban Sangat Tidak Setuju (STS).

Proses validasi alat ukur menggunakan metode try out terpakai, sehingga skala disebar satu kali dan digunakan untuk validasi instrumen. Selanjutnya skor pada item yang tidak valid tidak diikutkan dalam perhitungan. Detail penyebaran skala ditulis pada bagian prosedur penelitian.

Tabel 2. Blue Print Skala Nilai Dan Kebutuhan

\begin{tabular}{|c|c|c|c|}
\hline Nilai (Value) & Kebutuhan (Need Scale) & Nomer Item & Jumlah \\
\hline $\begin{array}{l}\text { Prestasi } \\
\text { (Achievement) }\end{array}$ & $\begin{array}{l}\text { Penggunaaan kemampuan (Ability } \\
\text { Utilization) } \\
\text { Prestasi (Achievement) }\end{array}$ & $\begin{array}{l}6,26,46,66,86 \\
14,34,54,74,94\end{array}$ & 10 \\
\hline $\begin{array}{l}\text { Kenyamanan } \\
\text { (Comfort) }\end{array}$ & $\begin{array}{l}\text { Kondisi kerja (Working Conditions) } \\
\text { Kompensasi (Compensation) } \\
\text { Keamanan (Security) } \\
\text { Variasi (Variety) } \\
\text { Kegiatan (Activity) } \\
\text { Kebebasan (Independence) }\end{array}$ & $\begin{array}{l}1,21,41,61,81 \\
2,22,42,62,82 \\
3,23,43,63,83 \\
4,44,64 \\
10,30,50,70,90 \\
20,40,60,80,100\end{array}$ & 28 \\
\hline Status (Status) & $\begin{array}{l}\text { Wewenang (Authority) } \\
\text { Status sosial (Social Status) } \\
\text { Pengakuan (Recognition) } \\
\text { Kemajuan (Advancement) }\end{array}$ & $\begin{array}{l}5,25,45,65,85 \\
7,27,47,67,87 \\
13,33,53,73,93 \\
15,35,55,75,95 \\
\end{array}$ & 20 \\
\hline $\begin{array}{l}\text { Azas } \\
\text { Mengutamakan } \\
\text { Orang Lain } \\
\text { (Altruism) }\end{array}$ & $\begin{array}{l}\text { Nilai moral (Moral Value) } \\
\text { Rekan kerja (Co-Workers) } \\
\text { Layanan sosial (Social Service) }\end{array}$ & $\begin{array}{l}11,31,51,71,91 \\
17,37,57,77,97 \\
18,38,58,78,98\end{array}$ & 15 \\
\hline Keamanan (Safety) & $\begin{array}{l}\text { Praktek kebijakan perusahaan } \\
\text { (Company Policies and Practices) } \\
\text { Pengawasrelasi manusia } \\
\text { (Supervision Human Relations) } \\
\text { Pengawas teknis (Supervision } \\
\text { Technical) }\end{array}$ & $\begin{array}{l}8,28,48,68,88 \\
9,29,49,69,89 \\
16,36,56,76,96\end{array}$ & 15 \\
\hline $\begin{array}{l}\text { Otonomi } \\
\text { (Autonomy) }\end{array}$ & $\begin{array}{l}\text { Tanggung jawab (Responsibilty) } \\
\text { Kreativitas (Creativity) }\end{array}$ & $\begin{array}{l}12,32,52,72,92 \\
19,39,59,79,99\end{array}$ & 10 \\
\hline & & Total & 98 \\
\hline
\end{tabular}

Tabel 3. Indeks Validitas Skala Nilai Kerja

\begin{tabular}{|c|c|}
\hline Dimensi Nilai & Indeks Validitas \\
\hline $\begin{array}{l}\text { Prestasi (Achievement) } \\
\text { Kenyamanan (Comfort) } \\
\text { Status (status ) } \\
\text { Azas Mengutamakan Orang Lain (Altruism) } \\
\text { Keamanan (Safety) } \\
\text { Otonomi (Autonomy) }\end{array}$ & $\begin{array}{l}0,378-0,593 \\
0,318-0,719 \\
0,323-0,611 \\
0,339-0,614 \\
0,359-0,610 \\
0,401 \quad 0,641\end{array}$ \\
\hline
\end{tabular}

Tabel 4. Indeks Reabilitas Skala Nilai Kerja

\begin{tabular}{lccc}
\hline \multicolumn{1}{c}{ Dimensi Nilai } & Alpha & rtabel & Keterangan \\
\hline & & & \\
Prestasi (Achievement) & 0,820 & 0,312 & Reliabel \\
Kenyamanan (Comfort) & 0,900 & 0,312 & Reliabel \\
Status (status ) & 0,847 & 0,312 & Reliabel \\
Azas Mengutamakan Orang Lain & 0,869 & 0,312 & Reliabel \\
(Altruism) & 0,854 & 0,312 & Reliabel \\
Keamanan (Safety) & 0,824 & 0,312 & Reliabel \\
Otonomi (Autonomy) & & & \\
\hline
\end{tabular}


Dari uji reliabilitas ditemukan alfa skala nilai kerja dengan keseluruhan indikator adalah 0.952 , yaitu reliabel, sehingga skala memiliki keandalan yang cukup tinggi.

Penyebaran skala dimulai dari tanggal 01 Agustus 2013 sampai dengan tanggal 31 Oktober 2013. Proses ini dilakukan peneliti secara bertahap dan bergantian. Waktu penelitian tidak tetap dikarenakan menyesuaikan dengan waktu yang disediakan oleh setiap subjek penelitian, sebelum menyebarkan skala, peneliti mengkonfirmasi dan menyesuaikan jadwal dengan subjek penelitian dan membicarakan prosedur pengambilan data yang lebih efisien.Penelitian dilakukan dengan beberapa cara, ada yang dititipkan oleh beberapa teman yang selanjutnya akan diberikan kepada subjek penelitian dan setelah diisi dikembalikan kembali kebeberapa teman tersebut dan peneliti kemudian

untuk diisi, kemudian peneliti mengambil data penelitian yang telah diisi tersebut.

\section{Teknik Analisis Data}

Setelah seluruh data terkumpul, peneliti melakukanentry data, validasi alat ukur, mengukur reliabilitas alat ukur, dan proses analisa data. Dalam proses ini peneliti menggunakan software perhitungan statistik SPSS for windows versi 13.0. Penelitian ini menggunakan tryout terpakai sehingga peneliti tidak perlu dua kali mengambil data untuk dianalisis. Selama penelitian berlangsung, terdapat hal-hal yang mendukung dan hal-hal yang tidak mendukung penelitian.

\section{HASIL DAN PEMBAHASAN}

\section{Hasil}

Tabel 5. Deskripsi Subjek Penelitian

\begin{tabular}{lcc}
\hline Kategori & Frekuensi & Persentase \\
\hline Usia & 64 & $64 \%$ \\
$0-30$ Tahun & 29 & $29 \%$ \\
$31-40$ Tahun & 7 & $7 \%$ \\
$41-50$ Tahun & & \\
& 32 & $32 \%$ \\
Tingkat Pendidikan & 68 & $68 \%$ \\
SMA / Sederajat & & \\
Strata 1 (S1) & & \\
& 44 & $44 \%$ \\
Pekerjaan & 56 & $56 \%$ \\
Pegawai Negeri & & \\
Karyawan Swasta & 61 & $61 \%$ \\
Lama Bekerja & 39 & $39 \%$ \\
$\leq 2$ Tahun & & \\
$>2$ Tahun & 29 & $29 \%$ \\
Status Pernikahan & 71 & $71 \%$ \\
$\quad$ Menikah & & \\
Belum Menikah &
\end{tabular}

mengambil data penelitian yang telah diisi tersebut. Cara yang lain adalah peneliti langsung mengatur jadwal bertemu kepada subjek penelitian dan memberikan skala penelitian
Kota Malang sebagai tempat penelitian nilai kerja pada wanita yang bekerja dengan jumlah subjek 100 orang karyawan, yang terdiri dari pegawai negeri sipil dan karyawan 
swasta. Subjek penelitian yang berusia kurang dari 30 tahun sebanyak 64 orang, yang berusia antara 31 sampai 40 tahun ada 29 orang dan yang berusia antara 41 dan 50 tahun sebanyak 7 orang. Menurut tingkat pendidikannya jumlah wanita yang bekerja yang memiliki tingkat pendidikan SMA/Sederajat sebanyak 32 orang dan yang memiliki tingkat pendidikan Strata 1 (S1) sebanyak 68 orang.Ditinjau dari jenis pekerjaannya, subjek yang bekerja sebagai pegawai negeri sipil sebanyak 44 orang dan yang bekerja sebagai karyawan swasta sebanyak 56 orang. Sedangkan ditinjau dari lama bekerja, jumlah karyawan yang bekerja kurang atau sama dengan 2 tahun sebanyak 69 orang dan yang lebih dari 2 tahun sebanyak 39 orang. Dan terakhir, dilihat dari status pernikahannya adalah 29 orang dengan status sudah menikah dan 71 orang memiliki status belum menikah.

Sesuai dengan hasil analisa Z-Score yang tercermin pada tabel 6, perolehan prosentase pada masing-masing tingkat nilai kerja dimulai dari ranking tertinggi adalah dimensi nilai otonomi (Autonomy), yaitu sebanyak $28 \%$ atau 28 orang, kemudian diikuti dengan nilai prestasi (Achievement) dan azas mengutamakan orang lain (Altruism) yang sama-sama memiliki prosentase sebanyak $20 \%$, dan berikutnya adalah nilai status (Status) dengan prosentase 18\%, selanjutnya adalah nilai kenyamanan (Comfort) dengan prosentase sebanyak 14\%, sedangkan nilai terbawah adalah nilai keamanan (Safety) dengan perolehan prosentase sebanyak $0 \%$.

Tabel 6. Hasil Tabulasi Ranking Nilai Kerja Tertinggi

Berdasarkan Analisa Z-Score

\begin{tabular}{lcc}
\hline \multicolumn{1}{c}{ Dimensi Nilai } & Frekuensi & Persentase \\
\hline Prestasi (Achievement) & 20 & $\mathbf{2 0 \%}$ \\
Kenyamanan (Comfort) & 14 & $14 \%$ \\
Status (Status) & 18 & $18 \%$ \\
Azas Mengutamakan Orang & 20 & $20 \%$ \\
Lain (Altruism) & 0 & $0 \%$ \\
Keamanan (Safety) & 28 & $\mathbf{2 8 \%}$ \\
Otonomi (Autonomy) & 100 & $\mathbf{1 0 0 \%}$ \\
\hline \multicolumn{1}{c}{ Total } & &
\end{tabular}




Tabel 7. Hasil Tabulasi Ranking Nilai Kerja Tertinggi Berdasarkan Z-Score Berdasarkan Usia

\begin{tabular}{rccccccc}
\hline \multirow{2}{*}{ Usia } & \multicolumn{5}{c}{ Dimensi Nilai } & \multirow{2}{*}{ Total } \\
\cline { 2 - 6 } & (Achievement) & (Comfort) & (Status) & (Altruism) & (Safety) & (Autonomy) & \\
\hline $0-30$ & $17(26,6 \%)$ & $12(18,8 \%)$ & $15(23,4 \%)$ & $13(20,3 \%)$ & $0(0 \%)$ & $7(10,9 \%)$ & $64(100 \%)$ \\
$31-40$ & $3(10,3 \%)$ & $2(6,9 \%)$ & $3(10,3 \%)$ & $4(13,8 \%)$ & $0(0 \%)$ & $17(58,6 \%)$ & $29(100 \%)$ \\
$41-50$ & $0(0 \%)$ & $0(0 \%)$ & $0(0 \%)$ & $3(42,9 \%)$ & $0(0 \%)$ & $4(57,1 \%)$ & $7(100 \%)$ \\
\hline
\end{tabular}

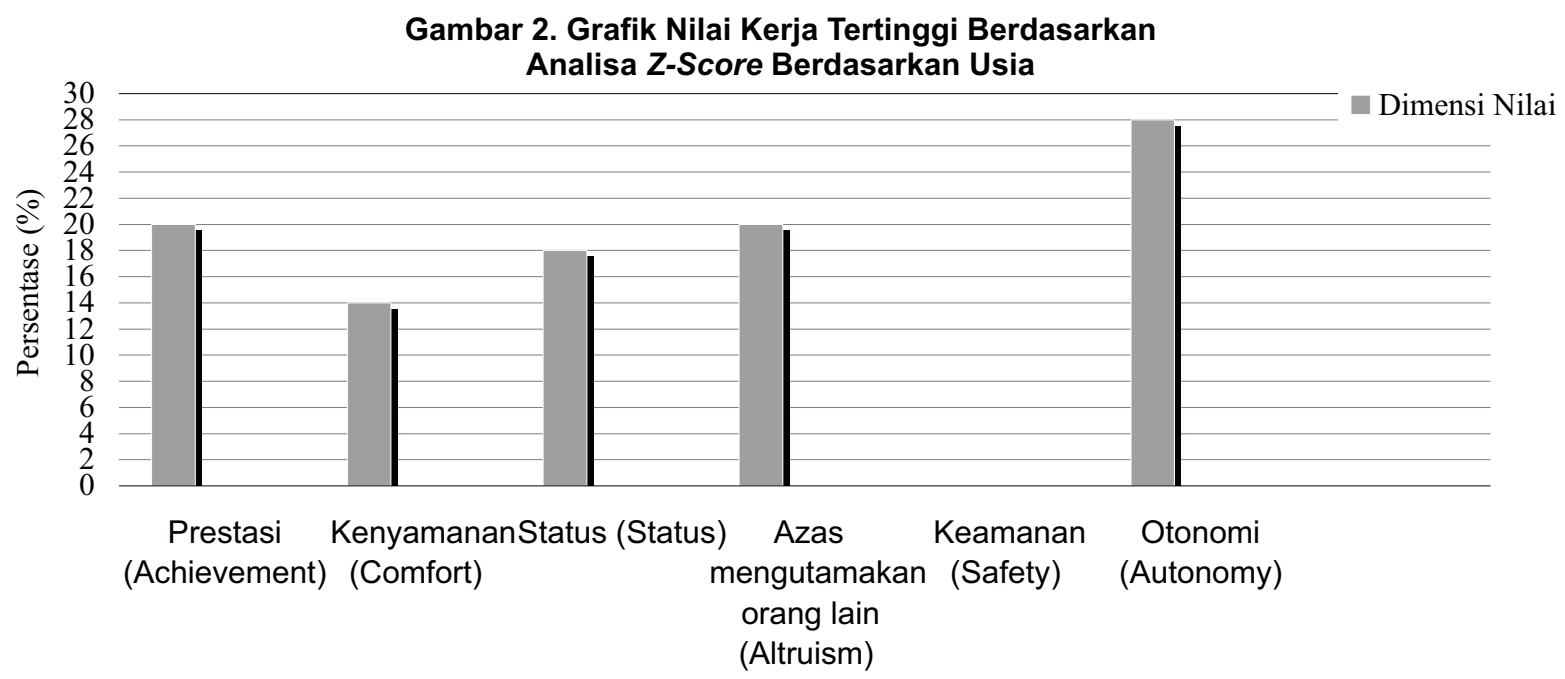

Berdasarkan tabel 7, tingkat nilai kerja pada wanita yang bekerja jika ditinjau dari usia, diurutkan dari dimensi nilai kerja yang memiliki prosentase tertinggi ke dimensi nilai yang memiliki prosentase terendah saat berumur kurang dari 30 tahun adalah nilai prestasi (Achievement) sebanyak 17 orang $(26,6 \%)$, status (Status) sebanyak 15 orang $(23,4 \%)$, azas mengutamakan orang lain (Altruism) sebanyak 13 orang $(20,3 \%)$, kenyamanan (Comfort) sebanyak 12 orang $(18,8 \%)$, otonomi (Autonomy) sebanyak 7 orang $(10,9 \%)$ dan keamanan (Safety) sebanyak $0(0 \%)$.

Ketika menginjak usia diantara 31 - 40 tahun, dimensi nilai tertinggi adalah otonomi
(Autonomy) sebanyak 17 orang $(58,6 \%$ ), azas mengutamakan orang lain (Altruism) sebanyak 4 orang $(13,8 \%)$, prestasi (Achievement) sebanyak 3 orang $(10,3 \%)$, status (Status) sebanyak 3 orang $(10,3 \%)$, kenyamanan (Comfort) sebanyak 2 orang $(6,9 \%)$ dan keamanan (Safety) sebanyak 0 $(0 \%)$.

Dan saat usia diantara 41 dan 50 tahun, dimensi nilai tertinggi adalah otonomi (Autonomy) sebanyak 4 orang $(57,1 \%)$, azas mengutamakan orang lain (Altruism) sebanyak 3 orang (42,9\%), dan sisanya adalah prestasi (Achievement), status (Status), kenyamanan (Comfort) dan keamanan (Safety) masing-masing sebanyak $(0 \%)$.

Tabel 8. Hasil Tabulasi Ranking Nilai Kerja Tertinggi

Berdasarkan Z-Score Berdasarkan Tingkat Pendidikan

\begin{tabular}{cccccccc}
\hline \multirow{2}{*}{$\begin{array}{c}\text { Tingkat } \\
\text { Pendidikan }\end{array}$} & \multicolumn{5}{c}{ Dimensi Nilai } & \multirow{2}{*}{ Total } \\
\cline { 2 - 6 } & (Achievement) & (Comfort) & (Status) & (Altruism) & (Safety) & (Autonomy) & \\
SMA & $9(28,1 \%)$ & $5(15,6 \%)$ & $6(18,8 \%)$ & $6(18,8 \%)$ & $0(0 \%)$ & $6(18,8 \%)$ & $32(100 \%)$ \\
S 1 & $11(16,2 \%)$ & $9(13,2 \%)$ & $12(17,6 \%)$ & $14(20,6 \%)$ & $0(0 \%)$ & $22(32,4 \%)$ & $68(100 \%)$ \\
\hline
\end{tabular}






Pada tabel 8 tercermin tingkat nilai kerja ditinjau dari tingkat pendidikan, diurutkan dari dimensi nilai kerja yang memiliki prosentase tertinggi ke dimensi nilai yang memiliki prosentase terendah yang hanya menempuh pendidikan SMA/Sederajat adalah nilai prestasi (Achievement) sebanyak 9 orang $(28,1 \%)$, otonomi (Autonomy) sebanyak 6 orang $(18,8 \%)$, status (Status) sebanyak 6 orang $(18,8 \%)$, azas mengutamakan orang lain (Altruism) sebanyak 6 orang $(18,8 \%)$, kenyamanan
(Comfort) sebanyak 5 orang $(15,6 \%)$, dan keamanan (Safety) sebanyak $0(0 \%)$.

Pada wanita yang bekerja dengan tingkat pendidikan S1, dimensi nilai tertinggi adalah otonomi (Autonomy) sebanyak 22 orang $(32,4 \%)$, azas mengutamakan orang lain (Altruism) sebanyak 14 orang $(20,6 \%)$, status (Status) sebanyak 12 orang $(17,6 \%)$, prestasi (Achievement) sebanyak 11 orang $(16,2 \%)$, kenyamanan (Comfort) sebanyak 9 orang $(13,2 \%)$ dan keamanan (Safety) sebanyak $0(0 \%)$.

Tabel 9. Hasil Tabulasi Ranking Nilai Kerja Tertinggi Berdasarkan Z-Score Berdasarkan Pekerjaan

\begin{tabular}{|c|c|c|c|c|c|c|c|}
\hline \multirow{2}{*}{ Pekerjaan } & \multicolumn{6}{|c|}{ Dimensi Nilai } & \multirow{2}{*}{ Total } \\
\hline & (Achievement) & (Comfort) & (Status) & (Altruism) & (Safety) & (Autonomy) & \\
\hline PNS & $12(27,3 \%)$ & $6(13,6 \%)$ & $12(27,3 \%)$ & $11(25,0 \%)$ & $0(0 \%)$ & $3(6,8 \%)$ & $44(100 \%)$ \\
\hline $\begin{array}{l}\text { Karyawan } \\
\text { Swasta }\end{array}$ & $8(14,3 \%)$ & $8(14,3 \%)$ & $6(10,7 \%)$ & $9(16,1 \%)$ & $0(0 \%)$ & $25(44,6 \%)$ & $56(100 \%)$ \\
\hline
\end{tabular}

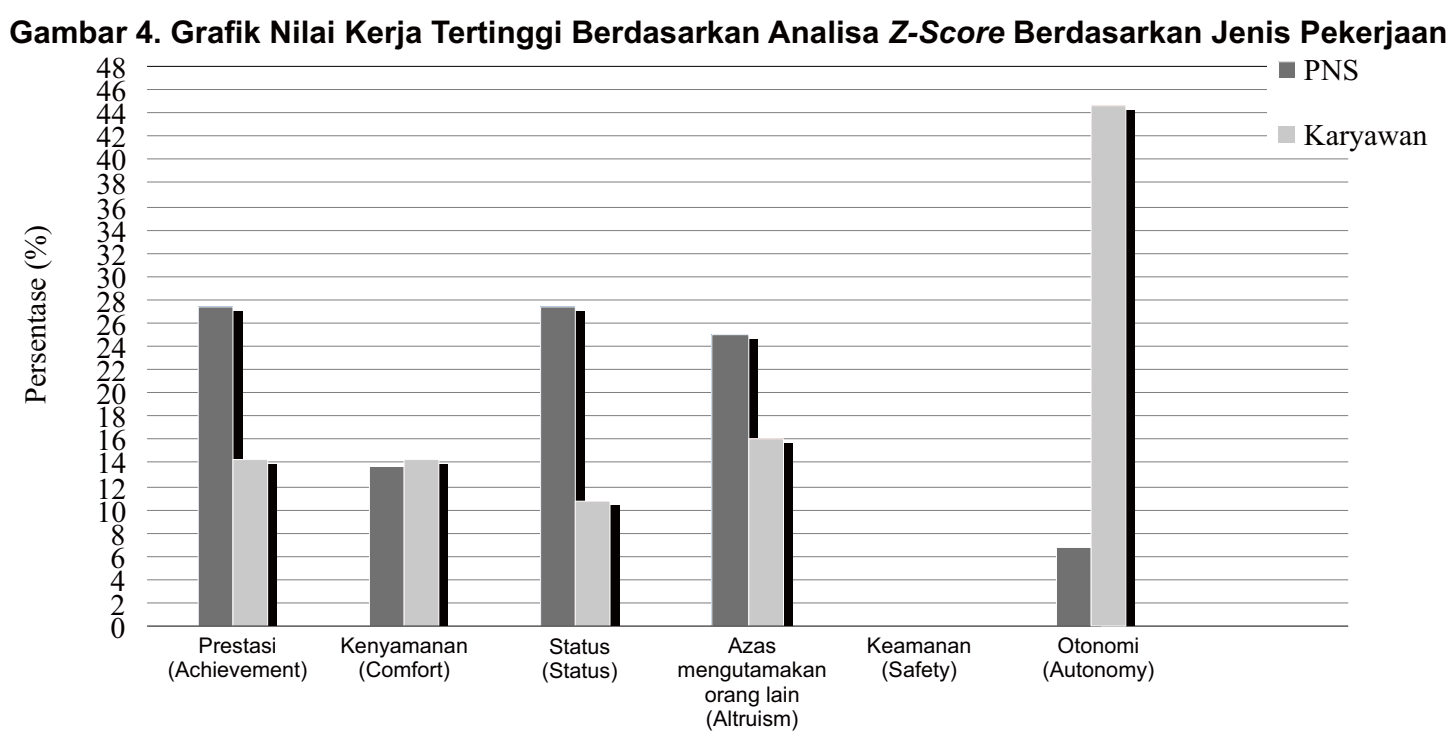


Pada tabel 9 tercermin tingkat nilai kerja ditinjau dari jenis pekerjaan, diurutkan dari dimensi nilai kerja yang memiliki prosentase tertinggi ke dimensi nilai yang memiliki prosentase terendah yang bekerja sebagai pegawai negeri sipil adalah nilai prestasi (Achievement) sebanyak 12 orang $(27,3 \%)$, status (Status) sebanyak 12 orang $(27,3 \%)$, azas mengutamakan orang lain (Altruism) sebanyak 11 orang (25\%), kenyamanan (Comfort) sebanyak 6 orang $(13,6 \%)$, otonomi (Autonomy) sebanyak 3 orang $(6,8 \%)$, dan keamanan (Safety) sebanyak 0 $(0 \%)$.

Pada wanita yang bekerja dengan jenis pekerjaan sebagai karyawan swasta, dimensi nilai tertinggi adalah otonomi (Autonomy) sebanyak 25 orang $(44,6 \%)$, azas mengutamakan orang lain (Altruism) sebanyak 9 orang $(16,1 \%)$, prestasi (Achievement) sebanyak 8 orang $(14,3 \%)$, kenyamanan (Comfort) sebanyak 8 orang $(14,3 \%)$, status (Status) sebanyak 6 orang $(10,7 \%)$ dan keamanan (Safety) sebanyak $0(0 \%)$.
Pada tabel 10 tercermin tingkat nilai kerja ditinjau berdasarkan lama bekerja, diurutkan dari dimensi nilai kerja yang memiliki prosentase tertinggi ke dimensi nilai yang memiliki prosentase terendah yang bekerja kurang dari atau sama dengan 2 tahun adalah nilai prestasi (Achievement) sebanyak 20 orang $(32,8 \%)$, status (Status) sebanyak 14 orang (23\%), kenyamanan (Comfort) sebanyak 10 orang $(16,4 \%)$, otonomi (Autonomy) sebanyak 9 orang $(14,8 \%)$, azas mengutamakan orang lain (Altruism) sebanyak 8 orang $(13,1 \%)$ dan keamanan (Safety) sebanyak $0(0 \%)$.

Pada wanita yang bekerja dengan lama bekerja lebih dari 2 tahun, dimensi nilai tertinggi adalah otonomi (Autonomy) sebanyak 19 orang $(48,7 \%)$, azas mengutamakan orang lain (Altruism) sebanyak 12 orang $(30,8 \%)$, status (Status) sebanyak 4 orang $(10,3 \%)$, kenyamanan (Comfort) sebanyak 4 orang (10,3\%), prestasi (Achievement) sebanyak ( $0 \%)$ dan keamanan (Safety) sebanyak $0(0 \%)$.

Tabel 10. Hasil Tabulasi Ranking Nilai Kerja Tertinggi Berdasarkan Z-Score Berdasarkan Lama Bekerja

\begin{tabular}{cccccccc}
\hline $\begin{array}{c}\text { Lama } \\
\text { Bekerja }\end{array}$ & \multicolumn{5}{c}{ Dimensi Nilai } & \multirow{2}{*}{ Total } \\
\cline { 2 - 6 }$\leq 2$ Tahun & (Achievement) & (Comfort) & (Status) & (Altruism) & (Safety) & (Autonomy) & \\
$>2(32,8 \%)$ & $10(16,4 \%)$ & $14(23,0 \%)$ & $8(13,1 \%)$ & $0(0 \%)$ & $9(14,8 \%)$ & $61(100 \%)$ \\
$>2$ Tahun & $0(0 \%)$ & $4(10,3 \%)$ & $4(10,3 \%)$ & $12(30,8 \%)$ & $0(0 \%)$ & $19(48,7 \%)$ & $39(100 \%)$ \\
\hline
\end{tabular}




Nugroho Hadi Nur Hendri Putranto \& Tri Muji Ingarianti: "Nilai Kerja Pada Wanita”...(113 - 129)

Tabel 11. Hasil Tabulasi Ranking Nilai Kerja Tertinggi Berdasarkan Z-Score Berdasarkan Status Pernikahan

\begin{tabular}{|c|c|c|c|c|c|c|c|}
\hline \multirow{2}{*}{$\begin{array}{c}\text { Status } \\
\text { Pernikahan }\end{array}$} & \multicolumn{6}{|c|}{ Dimensi Nilai } & \multirow{2}{*}{ Total } \\
\hline & (Achievement) & (Comfort) & (Status) & (Altruism) & (Safety) & (Autonomy) & \\
\hline Menikah & $2(6,9 \%)$ & $1(3,4 \%)$ & $1(3,4 \%)$ & $7(24,1 \%)$ & $0(0 \%)$ & $18(62,1 \%)$ & $29(100 \%)$ \\
\hline $\begin{array}{l}\text { Belum } \\
\text { Menikah }\end{array}$ & $18(25,4 \%)$ & $13(18,3 \%)$ & $17(23,9 \%)$ & $13(18,3 \%)$ & $0(0 \%)$ & $10(14,1 \%)$ & $71(100 \%)$ \\
\hline
\end{tabular}

Gambar 6. Grafik Nilai Kerja Tertinggi Berdasarkan Analisa Z-Score Berdasarkan StatusPernikahan

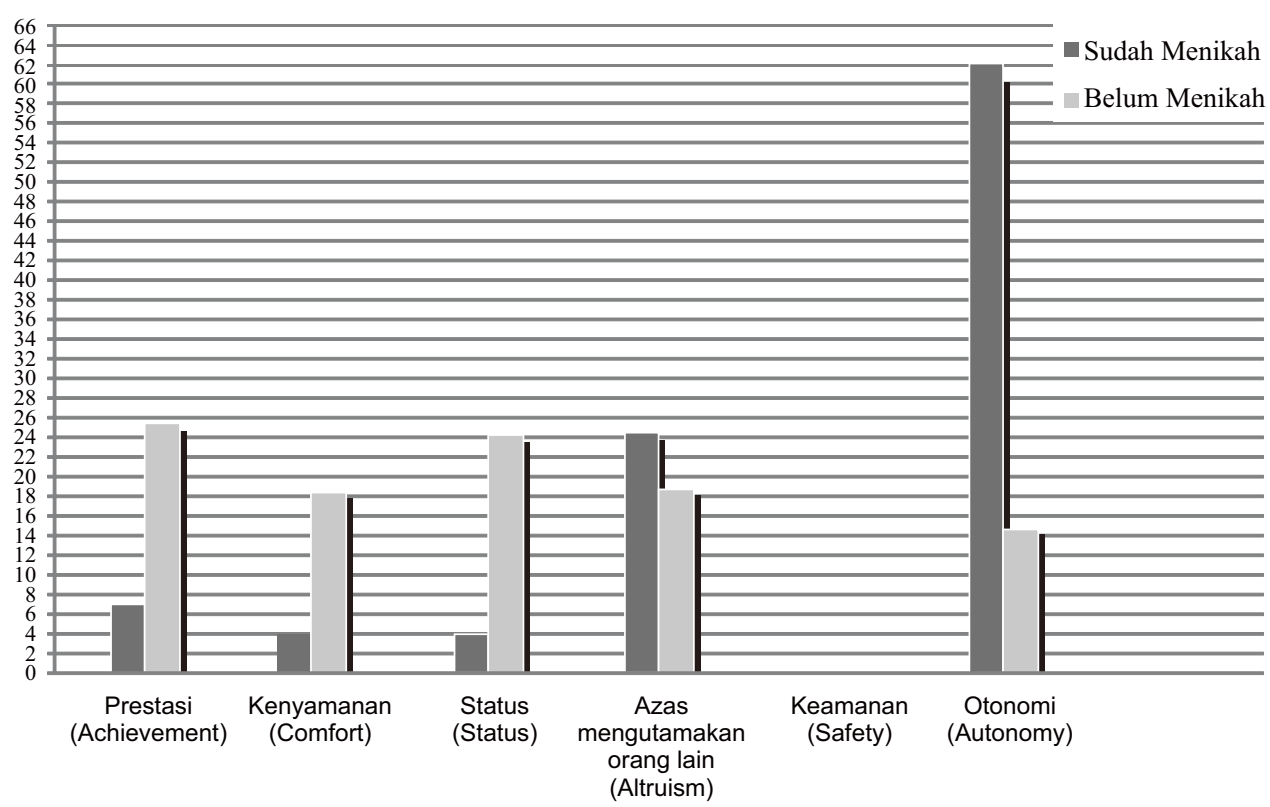

Melihat gambaran tabel 11 tercermin tingkat nilai kerja ditinjau berdasarkan status pernikahan, diurutkan dari dimensi nilai kerja yang memiliki prosentase tertinggi ke dimensi nilai yang memiliki prosentase terendah yang memiliki status sudah menikah adalah nilai otonomi (Autonomy) sebanyak 18 orang $(62,1 \%)$, azas mengutamakan orang lain (Altruism) sebanyak 7 orang $(24,1 \%)$, prestasi (Achievement) sebanyak 2 orang (6,9\%), kenyamanan (Comfort) sebanyak 1 orang $(3,4 \%)$, status (Status) sebanyak 1 orang $(3,4 \%)$ dan keamanan (Safety) sebanyak 0 $(0 \%)$.

Pada wanita yang memiliki status belum menikah dimensi nilai tertinggi adalah prestasi (Achievement) sebanyak 18 orang $(25,4 \%)$, status (Status) sebanyak 17 orang $(23,9 \%)$, kenyamanan (Comfort) sebanyak 13 orang $(18,3 \%)$, azas mengutamakan orang lain
(Altruism) sebanyak 13 orang (18,3\%), otonomi (Autonomy) sebanyak 10 orang (14,1\%) dan keamanan (Safety) sebanyak $0(0 \%)$.

\section{Pembahasan}

Melihat penelitian nilai kerja pada wanita yang bekerja di kota Malang menunjukkan hasil bahwa tingkat prosentase dimensi nilai tertinggi adalah nilai otonomi (Autonomy), yaitu kemudian diikuti dengan nilai prestasi (Achievement) dan azas mengutamakan orang lain (Altruism) yang memiliki prosentase yang sama dan berikutnya adalah nilai status (Status), selanjutnya adalah nilai kenyamanan (Comfort), sedangkan peringkat nilai terbawah adalah nilai keamanan (Safety).

Dari hasil penelitian ini juga ditemukan bahwadimensi nilai otonomi (Autonomy) 
memiliki prosentase tertinggi diantara dimensi nilai yang lain secara umum, hal ini dapat dilihat dari berbagai tinjauan, seperti pada hasil tabulasi ranking analisa Z-Score. Dimensi nilai otonomi (Autonomy) ini menurut kebutuhannya, terkait erat dengan kreatifitas dan tanggung jawab yang membuat tiap individu merasa bahwa pentingnya lingkungan yang selalu merangsang inisiatif untuk selalu mandiri.Tingginya dimensi nilai otonomi (Autonomy) bisa dipengaruhi berbagai macam hal. Menurut (Eccles, 1994) dalam studi longitudinalnya, ia menemukan bahwa perempuan memiliki nilai lebih daripada pria tentang pentingnya mengorbankan pekerjaan demi keluarga. Selain itu Nilai kerja merupakan ekspresi kognitif dari berbagai kebutuhan atau tujuan yang ditujukan melalui kerja seseorang dan bekerja, termasuk keamanan moneter, interaksi sosial, stimulasi intelektual, status, harga diri dan kebutuhan aktualisasi diri.

Dari data demografis yang tercantum dalam instrumen penelitian menggambarkan usia subjek yang beragam. Dalam klasifikasi usia tersebut, terdapat perbedaan dimensi nilai tertinggi pada masing-masing usia, saat berusia kurang dari 30 tahun, dimensi nilai tertinggi adalah nilai prestasi (Achievement) dengan prosentase $26,6 \%$, kemudian saat berusia antara $31-40$ tahun berubah menjadi nilai otonomi (Autonomy) yang memiliki prosentase tertinggi dengan jumlah $58,6 \%$, dan saat berusia antara $41-50$ tahun dimensi nilai otonomi (Autonomy) tetap memperoleh prosentase tertinggi sebanyak $57,1 \%$. Hal ini mencerminkan bahwa nilai kerja pada pekerjaan dan karir adalah ekspresi dari konsep diri yang terus mengalami proses dan berkembang dari waktu ke waktu selama rentang hidup. Konsep diri berkembang dari waktu ke waktu, produk dari pematangan fisik dan mental, dan individu menerapkan konsep diri mereka ke dalam karir yang akan memberikan cara yang paling efisien dari ekspresi diri. Pada usia muda, wanita yang bekerja cenderung memiliki nilai prestasi (Achievement) lebih tinggi, mereka biasanya baru saja menyelesaikan pendidikan dan pelatihan mereka dan baru memulai memasuki dunia kerja, pada teori tahap perkembangan karir Super (Winkel dan Sri Hastuti, 2005: 632) tahap ini biasa disebut tahap eksplorasi (Exploration), kemudian mereka mempersempit pemilihan karir dan memulai perilaku yang memungkinkan mereka diterima di lingkungan kerja mereka sehingga kebutuhan untuk berprestasi dan pemanfaatan kemampuan mereka harus terpenuhi. Kemudian saat mereka sudah berusia lebih tua, yang terjadi adalah orang dewasa yang lebih tua akan memilih untuk memfokuskan tenaga mereka pada tugas dan kegiatan yang bermakna bagi mereka, sudut pandang ini disampaikan oleh $\mathrm{K}$. Warner Schaie (1997) dan menyebut fase reintegratif dimana kebutuhan untuk mencari pengetahuan lebih lanjut menurun dan kebutuhan untuk memonitor keputusankeputusan juga menurun, sehingga nilai otonomi (Autonomy) menjadi lebih tinggi, karena tanggung jawab mereka lebih fokus pada diri mereka dan yang berkaitan dengan mereka, seperti contohnya keluarga. Pada teori tahap perkembangan karir Super tahap ini biasa disebut tahap pemeliharaan (Maintenance), individu berusaha untuk meneruskan atau memelihara situasi pekerjaan.Pekerjaan yang dilakukan dan konsep diri (self-concept) mempunyai hubungan yang erat. Keduanya terjalin oleh proses perubahan dan penyesuaian yang kontinyu. Pada intinya individu berkepentingan untuk melanjutkan aspek-aspek pekerjaan yang memberikan kepuasan, dan merubah atau memperbaiki aspek-aspek pekerjaan yang tidak menyenangkan, tetapi tidak sampai individu itu meninggalkan pekerjaan tersebut untuk berganti dengan pekerjaan yang lain. 
Memiliki pendidikan dan gelar universitas sangat banyak membantu dan hal ini dihubungkan dengan kemajuan karir yang lebih tinggi (Bray \& Howard, 1983; Golan, 1986).Dalam penelitian ini 32\% merupakan lulusan SMAdan sisanya $68 \%$ dari keseluruhan subjek merupakan lulusan sarjana (strata 1/S1). Pada subjek lulusan SMA dimensi nilai tertinggi adalah nilai prestasi (Achievement), sedangkan pada subjek lulusan sarjana (strata 1/S1) dimensi nilai yang memiliki prosentase tertinggi adalah nilai otonomi (Autonomy).Hal tersebut menggambarkan bahwa perbedaan pengalaman-pengalamansosial yang didapat dari tingkat pendidikan akan memberikan kemampuan yang berbeda, kemampuan yang dimiliki dari perbedaan inilah yang akhirnya menjadi penyesuaian di tempat kerja dan akan memberikan implikasi yang berbeda pada kebutuhan tiap orang dan menjadi nilai kerja yang berbeda pula dari tiap jenjang pendidikannya. Selain itu, ada konsensus di literatur bahwa kepentingan sosial terkait dengan pentingnya hubungan di tempat kerja (Smith \& Campbell, 2009; Hirschi, 2008).

Orang-orang yang memiliki gelar sarjana cenderung memiliki dimensi nilai yang lebih tinggi pada dimensi nilai otonomi (Autonomy) dibandingkan dengan orang -orang yang tidak memiliki ijazah sekolah tinggi. Main Study: Relationships of Work Values with Gender, Race/Ethnic Group, and Education : (Rod McCloy, Gordon Waugh, Gina Medsker 1999). Jenis pekerjaan yang berbeda menuntut keterampilan dan kemampuan yang berbeda, sehingga kebutuhan tiap seseorang akan berbeda pula. Pada wanita yang bekerja sebagai pegawai negeri sipil, nilai prestasi (Achievement) dan nilai status (Status) adalah nilai tertinggi dibandingkan dimensi nilai yang lain dengan prosentase yang sama sebanyak $27,3 \%$, hal ini mungkin disebabkan karena adanya penilaian kerja rutin yang membutuhkan prestasi yang baik dan penggunaan kemampuan tiap individu, sehingga wanita yang bekerja sebagai pegawai negeri sipil dituntut oleh hal semacam itu. Untuk nilai status (Status) yang juga mendapatkan prosentasi tinggi mungkin dikarenakan pandangan atau penilaian masyarakat indonesia yang pada umumnya ketika melihat seseorang bekerja sebagai pegawai negeri sipil akan terdapat pengakuan dan status sosial yang berbeda.

Berbeda dengan wanita yang bekerja sebagai karyawan swasta, pada penelitian ini dimensi nilai otonomi (Autonomy) memiliki prosentase nilai tertinggi sebanyak $44 \%$, hal ini mungkin disebabkan pada wanita yang bekerja sebagai karyawan swasta lebih membutuhkan kreatifitas dan tanggung jawab yang lebih, sehingga wanita yang bekerja di sebagai karyawan swasta menyesuaikan dirinya dengan kebutuhannya. Hal ini mendukung hasil penelitian yang menyim-pulkan bahwa terdapat perbedaan faktor-faktor motivator (prestasi, pengakuan, pekerjaan itu sendiri, tanggung jawab, pertumbuhan dan perkembangan) pada karyawan yang puas, baik itu pegawai negeri sipil maupun karyawan swasta, secara signifikan dibandingkan dengan karyawan yang tidak puas, dimana kelompok yang puas rata-rata menilai faktor-faktor motivator lebih tinggi dibandingkan dengan kelompok yang tidak puas (Yuki utami dan Joko Suyono, 2003).

Ada perbedaan dimensi nilai pada wanita yang bekerja dilihat dari lama bekerjanya. Pada wanita yang bekerja kurang dari atau sama dengan 2 tahun memiliki nilai prestasi (Achievement) sebagai nilai tertinggi dengan prosentase sebanyak $32,8 \%$ dan pada wanita yang bekerja lebih dari 2 tahun memiliki nilai otonomi (Autonomy) sebagai nilai yang memiliki prosentase teringgi sebanyak $48,7 \%$. Dalam setiap pengalaman bekerja, tiap orang akan mendapatkan stimulus baru dan mengembangkan beberapa kemampuan dan kebutuhan yang berbeda, 
selama waktu tertetntu dalam bekerja tiap orang akan mengalami perubahan pada kemampuan, nilai dan gaya dalam bekerja.

Perbedaan dimensi nilai pada wanita yang bekerja dilihat dari status pernikahan, dimensi nilai kerja yang memiliki prosentase tertinggi adalah dimensi nilai otonomi (Autonomy) pada wanita yang sudah menikah, sedangkan pada wanita yang belum menikah, dimensi nilai tertinggi adalah nilai (prestasi (Achievement). Ketika wanita belum menikah dan telah bekerja kemungkinan besar kebutuhan untuk berprestasi dan perasaan untuk menggunakan kemampuannya sangat tinggi, berbeda dengan wanita yang sudah menikah, fokus mereka mungkin pada tanggung jawab dan rasa kemandirian serta kestabilan pada pekerjaan, sehinga mereka hanya merubah aspek-aspek pekerjaan yang bersifat tidak menyenangkan bagi mereka.

\section{SIMPULAN}

Berdasarkan analisa data Z-Score dapat ditarik kesimpulan bahwa wanita yang bekerja memiliki tingkat prosentase dimensi nilai tertinggi atau yang paling dominan pada nilai otonomi (Autonomy),kemudian diikuti dengan nilai prestasi (Achievement) dan azas mengutamakan orang lain (Altruism) yang memiliki prosentase yang sama dan berikutnya adalah nilai status (Status), selanjutnya adalah nilai kenyamanan (Comfort), sedangkan peringkat nilai terbawah adalah nilai keamanan (Safety).

Pada wanita yang bekerja dimensi nilai kerja yang paling mendominasi dan berbeda dapat dilihat dari beberapa aspek kehidupan. Dimensi nilai kerja lebih banyak mendominasi pada dua dimensi nilai, yaitu pada nilai prestasi (Achievement) dan dimensi nilai otonomi (Autonomy). Dimensi nilai kerja pada karyawan wanita berusia muda lebih banyak pada nilai prestasi
(Achievement), begitupun dengan wanita yang hanya mengenyam pendidikan SMA, dan wanita yang bekerja sebagai pegawai negeri sipil. Namun ketika usia mereka beranjak tua, dimensi nilai otonomi (Autonomy) lebih mendominasi, begitupun dengan wanita yang mengenyam pendidikan sampai sarjana serta kebanyakan wanita yang bekerja sebagai karyawan swasta. Ditinjau dari lama bekerja dan status pernikahan dimensi nilai prestasi (Achievement) mendominasi pada wanita yang bekerja kurang dari atau sama dengan 2 tahun dan wanita yang belum menikah, namun pada wanita yang sudah menikah dan bekerja lebih dari dua tahun, dimensi nilai otonomi (Autonomy) kemudian menjadi dimensi nilai yang lebih mendominasi.

Implikasi dari penelitian ini meliputi: pertama, diharapkan wanita yang bekerja yang telah mengetahui dimensi nilai yang paling dominan di dalam dirinya dapat memahami bahwa dimensi nilai kerja dapat memberikan informasi tambahan untuk membantu mengambil keputusan dan mempersempit pilihan karir dengan tujuan memilih pekerjaan yang lebih memuaskan.

Kedua, untuk tempat bekerja, dengan memahami nilai-nilai kerja karyawan dapat memberikan beberapa keuntungan dalam pelayanan menciptakan intervensi yang lebih efektif untuk meningkatkan kepuasan karyawan, seperti misalnya pemberian motivasi. Informasi tentang nilai kerja dapat memberikan pemahaman yang lebih dalam pilihan pekerjaan yang berbeda dan tempat bekerja dapat menggunakan informasi pada nilai-nilai kerja karyawan untuk mengembangkan program yang efektif untuk membantu dalam mempertahankan pekerja. Selain itu, dalam hal penerimaan atau seleksi karyawan baru, setiap tempat bekerja dapat memilih pendaftar kerja yang terbaik dan yang paling sesuai dengan nilai-nilai tempat bekerja itu sendiri. 
Ketiga, bagi peneliti selanjutnya dapat melanjutkan penelitian ini dengan meneliti lebih dalam mengenai aspek dimensi nilai kerja, seperti dimensi nilai prestasi (Achievement) dan dmensi nilai otonomi (Autonomy), serta dimensi nilai yang lain. Selain itu peneliti selanjutnya juga dapat membandingkan antara variabel nilai kerja pada wanita dengan nilai kerja pada pria, atau pengaruh variabel nilai kerja pada wanita terhadap kehidupan pernikahannya, agar mampu memberikan gambaran yang lebih lengkap dan lebih beragam, karena pada penelitian ini cakupan subjek yang diambil hanya pada wanita yang bekerja.

\section{Daftar Pustaka}

Azwar, Saifuddin. (2008). Reliabilitas dan Validitas: Pustaka Pelajar.

Baruch, Yehuda. (2004). Managing Careers. Glaslow: Bell And Baind Limited.

BLS Spotlight On Statistics: Women At Work (2 0111 ). http://www.bls.gov/ spotlight/2011/women at work.

Dawis, Rene V., \& Lofquist, Lloyd H. (1984). A Psychological Theory Of Work Adjustment: An Individual-Differences Model and Its Applications. Minneapolis: University of Minnesota Press.

Dayakisni, T., \& Yanuardi, S. (2004). Psikologi Lintas Budaya. Malang: UMM Press.

Hansen, Jo-Ida C., \& Leuty, Melanie E. (29 August 2011). Work Values Across Generations. Journal of Career Assessment from http://jca.sagepub.com /content/20/1/34.

Leung, S. Alvin (2008). International Handbook of Career Guidance: The Big Five Career Theories. China: The Chinese University of Hong Kong.

McCloy, Rod., Waugh, Gordon., Medsker, Gina. (1999). Main Study: Relationships of Work Values with Gender, Race/Ethnic Group, and Education. National Center for O*NET Development Employment Security Commission.
Perempuan dalam dilemma pengasuhan anak pekerjaan. (2011, 06 April). http://kompasiana.com/ibu-dananak/2011/04/06/perempuan-dalamdilemma-pengasuhan-anak-pekerjaan.

Santrock, John W. (2002). Life-Span Development: Perkembangan Masa Hidup, Edisi 5, Jilid II. Jakarta: Erlangga.

Weiss, David J., Dawis, Rene V., England, George W., \& Lofquist, Lloyd H. (April, 1964). Minnesota Studies In Vocational Rehabilitation: XVI - The Measurement Of Vocational Needs. Minneapolis: University of Minnesota Press.

Weiss, David J., Dawis, Rene V., England, George W., \& Lofquist, Lloyd H. (December, 1964). Minnesota Studies In Vocational Rehabilitation: XVIII - Construct Validation Studies of The Minnesota Importance Questionaire. Minneapolis: University of Minnesota Press.

Winarsunu, T. (2009). Statistik, Dalam Penelitian Psikologi \& Pendidikan. Malang: UMM Press.

Winter, David. Theory of work adjustment. Careers Group, University of London (www.careers.lon.ac.uk) from http://creativecommons.org/licenses/by$\mathrm{nc} / 2.0 / \mathrm{uk}$ 